\title{
Surgical ligation of patent ductus arteriosus in preterm neonates weighing less than 1500g: a 9-year single center experience
}

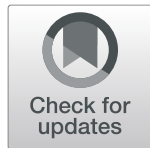

Jun Ho Lee ${ }^{1+}$, Hyun Ju Lee ${ }^{2+}$, Hyun-Kyung Park², Ja-Hye Ahn², Hee Sun Kim², Hyo Jun Jang ${ }^{1}$, Sun Kyun Ro ${ }^{3}$ and Hyuck Kim ${ }^{1 *}$ (D)

\begin{abstract}
Background: The aim of this study was to determine the feasibility and outcomes of early surgical ligation in preterm neonates with hemodynamically significant patent ductus arteriosus (HSPDA) and to investigate predictors for surgical treatment after unsuccessful medical management.

Methods: Medical records from the neonatal intensive care unit of Hanyang University Seoul Hospital from January 2010 to December 2018 were retrospectively reviewed. 233 preterm neonates weighing less than 1500g with HSPDA were enrolled in our study. Of these preterm neonates, 134 underwent surgical ligation and were subdivided into the early ligation group ( $n=49$; within 10 days of age) and the late ligation group $(n=85$; after 10 days of age).

Results: The mean gestational age and birth weight were significantly lower in the patent ductus arteriosus (PDA) ligation group than in the Non-ligation group $(p<0.001)$. PDA ductal diameter $>2.0 \mathrm{~mm}(p<0.001)$, low Apgar score at $5 \mathrm{~min}(p=0.033)$, and chorioamnionitis $(p=0.037)$ were the predictors for receiving surgical treatment for PDA. Early ligation was significantly associated with a low incidence of culture-proven sepsis $(p=0.004)$, mechanical ventilator time $>4$ weeks $(p=0.007)$, necrotizing enterocolitis stage $(\mathrm{NEC}) \geq \mathrm{III}(p=0.022)$, and intraventricular hemorrhage (IVH) grade $\geq$ III $(p=0.035)$.

Conclusions: Early surgical ligation minimizes the adverse effects of HSPDA in predicted preterm neonates who subsequently require surgical treatment for PDA. This result suggests that in preterm neonates weighing less than $1500 \mathrm{~g}$ with HSPDA that is unresponsive to medical treatment, delayed ductal closure should be avoided to reduce severe NEC, severe IVH, culture-proven sepsis, and facilitate earlier endotracheal extubation.
\end{abstract}

Keywords: Patent ductus arteriosus, Congenital heart disease, Preterm neonates

\footnotetext{
* Correspondence: khkim@hanyang.ac.kr

† Jun Ho Lee and Hyun Ju Lee contributed equally to this work.

'Department of Thoracic and Cardiovascular Surgery, Hanyang University

Seoul Hospital, Hanyang University School of Medicine, 222-1, Wangsimni-ro, Seongdong-gu, Seoul 04763, South Korea

Full list of author information is available at the end of the article
}

(C) The Author(s). 2020 Open Access This article is licensed under a Creative Commons Attribution 4.0 International License, which permits use, sharing, adaptation, distribution and reproduction in any medium or format, as long as you give appropriate credit to the original author(s) and the source, provide a link to the Creative Commons licence, and indicate if changes were made. The images or other third party material in this article are included in the article's Creative Commons. licence, unless indicated otherwise in a credit line to the material. If material is not included in the article's Creative Commons licence and your intended use is not permitted by statutory regulation or exceeds the permitted use, you will need to obtain permission directly from the copyright holder. To view a copy of this licence, visit http://creativecommons.org/licenses/by/4.0/ The Creative Commons Public Domain Dedication waiver (http://creativecommons.org/publicdomain/zero/1.0/) applies to the data made available in this article, unless otherwise stated in a credit line to the data. 


\section{Background}

Patent ductus arteriosus (PDA) is one of the most common congenital anomalies in premature neonates [1-3] and is associated with increased morbidity and mortality due to acute hemodynamic and respiratory compromise $[4,5]$. Although hemodynamically significant patent ductus arteriosus (HSPDA) in preterm neonates has been proven to increase morbidities such as necrotizing enterocolitis (NEC), intraventricular hemorrhage (IVH), bronchopulmonary dysplasia (BPD), heart failure and renal hypoperfusion [5-8], no randomized clinical trial has shown the benefit or efficacy of surgical ligation compared with no PDA ligation in preterm neonates with HSPDA that is refractory to medical treatment [9].

If pharmacologic treatment is contraindicated or fails, surgical ligation can be considered. Surgical ligation can be performed at the bedside in the neonatal intensive care unit (NICU) without a high risk of surgical morbidity or mortality [5]. Although PDA surgical ligation after unsuccessful medical treatment is a definitive treatment, studies on the proper timing of surgery for HSPDA are few $[4,6]$, and the proper timing of surgical ligation remains controversial.

The goal of this study was to analyze the feasibility of early surgical ligation (within 10 days of age) in preterm neonates with HSPDA and to investigate parameters that would be helpful for deciding on early surgery.

\section{Methods}

\section{Study populations}

Hanyang University Seoul Hospital is a tertiary referral center for patients with a multidisciplinary PDA team in Seoul, South Korea. All medical records of the NICU at our center from January 2010 to December 2018 retrospectively reviewed to identify preterm neonates weighing less than 1500g. Our institutional review board approved this study, and the need for patient consent was waived (IRB number; HYUH 2019-07-004-003).

\section{Medical treatment}

The direction of treatment for PDA was determined by the neonatologist. Most HSPDA patients were initially treated with 2 or 3 cycles of nonsteroidal antiinflammatory drugs (NSAIDs), such as indomethacin or ibuprofen. The protocol for indomethacin and ibuprofen treatment is described in Table 1. Ibuprofen was initially injected a dose of $10 \mathrm{mg} / \mathrm{kg}$ and additionally administered at $5 \mathrm{mg} / \mathrm{kg}$ at $24-\mathrm{h}$ intervals up to three cycles, if necessary. Contraindications to NSAID treatment were gastrointestinal bleeding, IVH grade $>$ I, poor urine output $(<0.6 \mathrm{~mL} / \mathrm{kg} / \mathrm{hr})$, high serum creatinine $(>1.8 \mathrm{mg} /$ $\mathrm{dL})$, high blood urea $(>30 \mathrm{mg} / \mathrm{dL})$, positive disseminated intravascular coagulation (DIC) profiles, or
Table 1 Protocol for NSAID treatment

\begin{tabular}{llll}
\hline Age at 1st dose & 1st & 2nd & 3rd \\
\hline Indomethacin $(\mathrm{mg} / \mathrm{kg})^{\text {a) }}$ & & & \\
$<48 \mathrm{~h}$ & 0.2 & 0.1 & 0.1 \\
$2-7$ days & 0.2 & 0.2 & 0.2 \\
$>7$ days & 0.2 & 0.25 & 0.25 \\
${\text { Ibuprofen }(\mathrm{mg} / \mathrm{kg})^{\text {b) }}}^{\text {b }}$ & 10 & 5 & 5 \\
\hline
\end{tabular}

NSAID nonsteroidal anti-inflammatory drug ${ }^{a}$ At 12 - to 24 -h intervals. ${ }^{b}$ At 24 -h intervals

thrombocytopenia $\left(<60,000 / \mathrm{mm}^{3}\right)$, as in our previous publication [4].

\section{Surgical treatment}

The decision to refer a preterm neonate with HSPDA to the department of Thoracic and Cardiovascular Surgery for surgical ligation after failure or due to contraindications of medical therapy was performed by a neonatologist and a pediatric cardiologist specialized in echocardiography. All operations were performed at the NICU bedside with the preterm neonate under general anesthesia. A left transaxillary mini-thoracotomy via the 3rd or 4th intercostal space was used as the PDA approach. The ductus arteriosus was ligated using a single medium or medium-large sized titanium Horizon clip (Teleflex Medical, Research Triangle Park, NC, USA). Immediately after the operation, the attending neonatologist checked with echocardiography to determine whether the PDA ligation was successful.

\section{Endpoints, definitions and follow-up}

The PDA ligation group comprised patients who underwent surgical ligation, and the Non-ligation group comprised patients who did not undergo surgical treatment. The PDA ligation group was divided into two subgroups: "early ligation (EL)" and "late ligation (LL)". As mentioned above, the EL group comprised patients who underwent PDA ligation within 10 days of age, and the LL group comprised patients who underwent surgery after 10 days of age.

The primary outcome of this study was a comparison of mortality between the PDA ligation and Non-ligation groups and the EL and LL groups. Secondary outcomes were factors associated with PDA surgical ligation and postoperative clinical outcomes such as NEC, BPD, IVH (grade $\geq \mathrm{III}$ ), sepsis, retinopathy of prematurity (ROP), and periventricular leukomalacia (PVL).

Echocardiography was performed within 3 days of birth, and subsequent echocardiographic parameters were obtained on day 6 ( \pm 1 day), day 9 ( \pm 1 day), and day 14 ( \pm 2 days) to identify symptomatic PDA in preterm neonates. Symptomatic PDA indicated HSPDA, which was defined as a ductal diameter $\geq 1.5 \mathrm{~mm}$, or a 
ratio of 1.5 or more of the size of the left atrium to the diameter of the aortic root on at least one echocardiography (HD11 Diagnostic Ultrasound Imaging System and Transducers; Philips Ultrasound, Bothell, WA, USA). This definition was based on the description of the previous publication [9]. Associated symptoms with HSPDA classified at our center have been described previously [4].

IVH was classified by Volpe's grading system [10]. Culture-proven sepsis was defined as the presence of positive findings in one or more blood cultures and clinical symptoms of infection. NEC was defined using Bell's modified staging criteria [11]. BPD was defined by Jobe and Bancalari's criteria [12]. The stages of ROP were classified using the international classification of retinopathy of prematurity [13].

\section{Statistical analyses}

Data were expressed as either the mean \pm standard deviation or frequency and proportion. Comparisons between groups were performed with chi-square tests and Fisher's exact tests for categorical variables. Two sample Student's $t$-tests were used for continuous variables when a normal distribution was found. The Mann-Whitney $U$ test was used for variables with skewed distributions. All tests were two-tailed. Logistic regression analysis was used to determine risk factors between the PDA ligation and Nonligation groups, and clinical morbidities between the EL and LL groups. Receiver operating characteristic (ROC) curves were constructed for the assessment of significant factors associated with PDA surgical ligation. All $p$ values of less than 0.05 were considered statistically significant. Statistical analysis was performed using SPSS, version 22.0 (SPSS, Chicago, IL, USA).

\section{Results}

A total of 233 preterm neonates weighing less than $1500 \mathrm{~g}$ with HSPDA were ultimately enrolled in our study (Fig. 1). Of these neonates, 134 (57.5\%) underwent surgical ligation and were subdivided into the EL group ( $n=49,36.6 \%)$ and the LL group ( $n=85,63.4 \%)$. The conditions of 99 neonates improved with medical treatment alone according to the protocol described at Table 1 . Nine preterm neonates with congenital anomalies were excluded, including two neonates with congenital tracheoesophageal fistula, one with congenital chylothorax, two with ileal atresia, two with Edwards syndrome, and two with dry lung syndrome.

The baseline characteristics of the patients in the PDA ligation and Non-ligation groups are summarized in Table 2. Regarding maternal characteristics, histologic chorioamnionitis was significantly higher in the PDA ligation group than in the Non-ligation group $(p=0.027)$, while pregnancy-induced hypertension (PIH) was significantly lower in the PDA ligation group than in the Non-ligation group $(p=0.031)$. Regarding neonate characteristics, gestational age (GA), birth weight, length, head circumference, and Apgar scores at $1 \mathrm{~min}$ and $5 \mathrm{~min}$ were significantly lower in the PDA ligation group than in the Non-ligation group. In contrast, time on a mechanical ventilator or on oxygen therapy, total parenteral nutrition and hospitalization, and age at PDA closure were significantly higher in the PDA ligation group than in the Non-ligation group. Additionally, PDA size $(2.13 \pm 0.84 \mathrm{~mm}$ vs $1.68 \pm 0.92 \mathrm{~mm}, p<0.001)$ and the proportion of preterm neonates with PDA ductal diameters larger than $2.0 \mathrm{~mm}$ ( 52.2 vs $22.2 \%, p<0.001)$ were significantly different between the PDA ligation and Non-ligation groups.

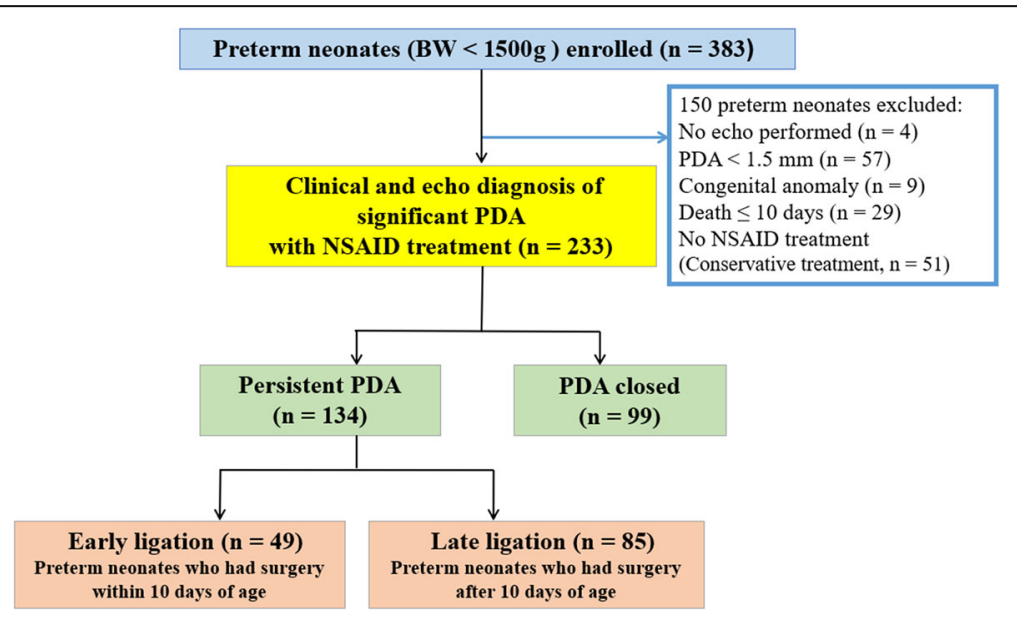

Fig. 1 Flow diagram of the study patients. BW, birth weight; PDA, patent ductus arteriosus; NSAID, nonsteroidal anti-inflammatory drug 
Table 2 Characteristics of preterm neonates of the PDA ligation and Non-ligation groups

\begin{tabular}{|c|c|c|c|}
\hline Variables & $\begin{array}{l}\text { PDA ligation } \\
(n=134)\end{array}$ & $\begin{array}{l}\text { Non-ligation } \\
(n=99)\end{array}$ & $p$ value \\
\hline \multicolumn{4}{|l|}{ Maternal characteristics } \\
\hline Maternal age, years & $32.58 \pm 4.30$ & $33.29 \pm 4.10$ & 0.205 \\
\hline Mother's education level & & & 0.946 \\
\hline High, n (\%) & $9(6.7)$ & $6(6.1)$ & \\
\hline Intermediate, n (\%) & $88(65.7)$ & $67(67.7)$ & \\
\hline Low, n (\%) & $37(27.6)$ & $26(26.3)$ & \\
\hline GDM & $10(7.5)$ & $10(10.1)$ & 0.488 \\
\hline $\mathrm{PIH}$ & $9(6.7)$ & $16(16.2)$ & 0.031 \\
\hline PPROM & $56(41.8)$ & $42(42.4)$ & $>0.999$ \\
\hline Histologic chorioamnionitis & $104(77.6)$ & $63(63.6)$ & 0.027 \\
\hline \multicolumn{4}{|l|}{ Neonate characteristics } \\
\hline Gestational age, weeks & $26.27 \pm 2.28$ & $27.37 \pm 1.90$ & $<0.001$ \\
\hline Birth weight, grams & $882.05 \pm 226.61$ & $1053.23 \pm 244.76$ & $<0.001$ \\
\hline Length & $33.69 \pm 4.59$ & $35.96 \pm 3.36$ & $<0.001$ \\
\hline Head circumference & $24.60 \pm 3.10$ & $25.58 \pm 2.37$ & 0.010 \\
\hline Cesarean section & $98(73.1)$ & $81(81.8)$ & 0.157 \\
\hline Male sex & $69(51.5)$ & $41(41.8)$ & 0.183 \\
\hline Apgar score at $1 \mathrm{~min}$ & $2.10 \pm 1.30$ & $2.73 \pm 1.33$ & $<0.001$ \\
\hline pgar score at $5 \mathrm{~min}$ & $4.58 \pm 1.67$ & $5.40 \pm 1.55$ & $<0.001$ \\
\hline Antenatal corticosteroids & $92(68.7)$ & $73(73.7)$ & 0.467 \\
\hline Postnatal corticosteroids & $57(42.5)$ & $31(31.3)$ & 0.101 \\
\hline Age at PDA closure, days & $15.57 \pm 8.94$ & $8.10 \pm 2.71$ & $<0.001$ \\
\hline Body weight at surgical ligation & $911.87 \pm 270.16$ & - & - \\
\hline IVH & $50(37.3)$ & $43(43.4)$ & 0.417 \\
\hline IVH grade II & $8(6)$ & $3(3)$ & 0.241 \\
\hline $\mathrm{IVH}$ grade $\geq \mathrm{II}$ & $21(15.7)$ & $17(17.2)$ & 0.858 \\
\hline$P V L$ & $10(7.5)$ & $9(9.1)$ & 0.809 \\
\hline Culture-proven sepsis & $83(61.9)$ & $55(55.6)$ & 0.347 \\
\hline NEC & $12(9.0)$ & $10(10.1)$ & 0.823 \\
\hline NEC stage $\geq$ III & $41(30.8)$ & $22(22.2)$ & 0.180 \\
\hline $\mathrm{BPD}$ & $74(55.6)$ & $44(44.9)$ & 0.112 \\
\hline $\mathrm{ROP}$ & $80(60.2)$ & $54(55.1)$ & 0.501 \\
\hline Days on mechanical ventilator & $30.62 \pm 18.63$ & $16.20 \pm 14.55$ & $<0.001$ \\
\hline Days of oxygen therapy & $68.70 \pm 52.01$ & $49.41 \pm 28.20$ & 0.001 \\
\hline TPN days & $44.44 \pm 25.64$ & $36.59 \pm 21.21$ & 0.014 \\
\hline Hospital days & $96.00 \pm 40.44$ & $79.89 \pm 28.56$ & 0.001 \\
\hline PDA size & $2.13 \pm 0.84$ & $1.68 \pm 0.92$ & 0.001 \\
\hline PDA ductal diameter $>2.0 \mathrm{~mm}$ & $70(52.2)$ & $22(22.2)$ & $<0.001$ \\
\hline Deaths & $1(0.7)$ & $2(2)$ & 0.576 \\
\hline
\end{tabular}

PDA patent ductus arteriosus, GDM gestational diabetes mellitus, $P I H$ pregnancy-induced hypertension, $P P R O M$ preterm premature rupture of membranes, $I V H$ intraventricular hemorrhage, $P V L$ periventricular leukomalacia, NEC necrotizing enterocolitis, $B P D$ bronchopulmonary dysplasia, $R O P$ retinopathy of prematurity, TPN total parenteral nutrition

Data are the mean \pm SD or number (\%) 
Table 3 Characteristics of preterm neonates of the early ligation and late ligation groups

\begin{tabular}{|c|c|c|c|}
\hline Variables & $\begin{array}{l}\text { Early ligation } \\
(n=49)\end{array}$ & $\begin{array}{l}\text { Late ligation } \\
(n=85)\end{array}$ & $p$ value \\
\hline \multicolumn{4}{|l|}{ Maternal characteristics } \\
\hline Maternal age, years & $33.22 \pm 5.16$ & $32.21 \pm 3.71$ & 0.205 \\
\hline Mother's education level & & & 0.835 \\
\hline High, n (\%) & $3(6.1)$ & $6(7.1)$ & \\
\hline Intermediate, n (\%) & $31(63.3)$ & $57(67.1)$ & \\
\hline Low, n (\%) & $15(30.6)$ & $22(25.9)$ & \\
\hline GDM & $2(4.1)$ & $8(9.4)$ & 0.325 \\
\hline $\mathrm{PIH}$ & $5(10.2)$ & $4(4.7)$ & 0.287 \\
\hline PPROM & $15(30.6)$ & $41(48.2)$ & 0.068 \\
\hline Histologic chorioamnionitis & $42(85.7)$ & $62(72.9)$ & 0.131 \\
\hline \multicolumn{4}{|l|}{ Neonate characteristics } \\
\hline Gestational age, weeks & $26.67 \pm 2.52$ & $26.04 \pm 2.11$ & 0.123 \\
\hline Birth weight, grams & $878.78 \pm 216.77$ & $883.94 \pm 233.34$ & 0.899 \\
\hline Length & $33.10 \pm 3.05$ & $34.03 \pm 5.27$ & 0.259 \\
\hline Head circumference & $24.48 \pm 2.30$ & $24.68 \pm 3.49$ & 0.719 \\
\hline Cesarean section & $41(83.7)$ & $57(67.1)$ & 0.044 \\
\hline Male sex & $24(49)$ & $41(48.2)$ & $>0.999$ \\
\hline Apgar score at $1 \mathrm{~min}$ & $2.08 \pm 1.27$ & $2.11 \pm 1.33$ & 0.918 \\
\hline Apgar score at $5 \mathrm{~min}$ & $4.76 \pm 1.58$ & $4.48 \pm 1.72$ & 0.367 \\
\hline Antenatal corticosteroids & $34(69.4)$ & $58(68.2)$ & $>0.999$ \\
\hline Postnatal corticosteroids & $17(34.7)$ & $40(47.1)$ & 0.205 \\
\hline Age at PDA closure, days & $8.18 \pm 2.14$ & $19.44 \pm 8.82$ & $<0.001$ \\
\hline Body weight at surgical ligation & $847.96 \pm 201.73$ & $948.71 \pm 297.58$ & 0.037 \\
\hline IVH & $18(36.7)$ & $32(37.6)$ & $>0.999$ \\
\hline IVH grade II & $4(8.2)$ & $4(4.7)$ & 0.240 \\
\hline IVH grade $\geq$ III & $4(8.2)$ & $17(20.2)$ & 0.086 \\
\hline PVL & $3(6.1)$ & $7(8.2)$ & 0.746 \\
\hline Culture-proven sepsis & $24(49)$ & $59(69.4)$ & 0.026 \\
\hline NEC & $18(36.7)$ & $24(28.2)$ & 0.337 \\
\hline NEC stage $\geq I I I$ & $2(4.1)$ & $15(17.6)$ & 0.030 \\
\hline BPD & $25(52.1)$ & $49(57.6)$ & 0.588 \\
\hline ROP & $32(66.7)$ & $48(56.5)$ & 0.273 \\
\hline Pneumothorax before ligation & $2(4.1)$ & $2(2.4)$ & 0.623 \\
\hline Pulmonary hemorrhage before ligation & $3(6.1)$ & $8(9.4)$ & 0.746 \\
\hline Gl hemorrhage before ligation & $1(2.0)$ & $7(8.2)$ & 0.257 \\
\hline Hypotension before ligation & $11(22.4)$ & $21(24.7)$ & 0.836 \\
\hline Hypotension after ligation & $2(4.1)$ & $3(3.5)$ & $>0.999$ \\
\hline Days on mechanical ventilator & $26.38 \pm 15.31$ & $33.02 \pm 19.95$ & 0.048 \\
\hline Days of oxygen therapy & $59.88 \pm 33.88$ & $74.51 \pm 56.89$ & 0.107 \\
\hline TPN days & $40.73 \pm 21.45$ & $47.41 \pm 28.36$ & 0.156 \\
\hline Hospital days & $94.53 \pm 38.86$ & $95.88 \pm 41.52$ & 0.853 \\
\hline PDA size & $2.06 \pm 0.67$ & $2.16 \pm 0.92$ & 0.481 \\
\hline PDA ductal diameter $>2.0 \mathrm{~mm}$ & $25(51.0)$ & $45(52.9)$ & 0.859 \\
\hline Deaths & $0(0)$ & $1(1.2)$ & $>0.999$ \\
\hline
\end{tabular}

GDM gestational diabetes mellitus, $P I H$ pregnancy-induced hypertension, $P P R O M$ preterm premature rupture of membranes, $I V H$ intraventricular hemorrhage, $P V L$ periventricular leukomalacia, NEC necrotizing enterocolitis, BPD bronchopulmonary dysplasia, ROP retinopathy of prematurity, Gl gastrointestinal, TPN total parenteral nutrition, $P D A$ patent ductus arteriosus

Data are the mean \pm SD or number $(\%)$ 
The baseline characteristics of the patients in the EL and LL groups are summarized in Table 3. Age at PDA closure $(8.18 \pm 2.14$ vs $19.44 \pm 8.82$ days, $p<0.001)$ and body weight at surgical ligation (847.96 \pm 201.73 vs $948.71 \pm 297.58 \mathrm{~g}, p=0.037$ ) were significantly different between the EL and LL groups. The baseline maternal characteristics and preoperative status did not differ significantly between the EL and LL groups. Regarding neonate characteristics, cesarean section was significantly higher in the EL group than in the LL group $(p=0.044)$. In contrast, culture-proven sepsis $(p=0.026)$, NEC stage $\geq$ III $(p=0.030)$, and time on a mechanical ventilator $(p=0.048)$ were significantly lower in the EL group than in the LL group.

No patients died during their operations. Two neonates required reoperation due to residual flow of PDA, as diagnosed by immediate postoperative transthoracic echocardiography. The residual flow was corrected with an additional metal clip. Three patients died during the postoperative hospital day. In the LL group, one neonate died 100 days after PDA ligation due to NEC. In the Non-ligation group, two neonates died 12 and 17 days after birth, and the cause of death was sepsis. There were no statistically significant differences in mortality rate between the PDA ligation and Non-ligation groups $(p=0.576)$, or between the EL and LL groups (p > 0.999).

The logistic regression analysis for factors associated with PDA surgical ligation is presented in Fig. 2. PDA ductal diameter $>2.0 \mathrm{~mm} \quad(p<0.001)$, low GA $(p=$ $0.004)$, low Apgar score at $5 \mathrm{~min}(p=0.033)$, and histologic chorioamnionitis $(p=0.037)$ remained significant after the analysis was controlled for GA, histologic chorioamnionitis, PIH, Apgar score at $5 \mathrm{~min}$, and PDA ductal diameter $>2.0 \mathrm{~mm}$.
The ROC curve for the ability to predict PDA surgical ligation showed that PDA ductal diameter $>2.0 \mathrm{~mm}$ predicted surgical treatment with an area under the curve (95\% confidence interval (CI)) of 0.650 (0.579-0.721). Histologic chorioamnionitis showed an area under the curve $(95 \% \mathrm{CI})$ of $0.570(0.495-0.645)$, making it statistically significant in relation to the factors associated with PDA surgical ligation (Fig. 3).

The clinical factors that were shown to affect the postoperative clinical outcomes of the patients (EL versus LL) in the multivariate model are shown in Fig. 4. Clinical outcomes with associations with $p<0.1$ in the univariate analyses were analyzed by multivariate logistic regression with adjustments for cesarean delivery, weight on PDA ligation and PDA diameter $>2.0 \mathrm{~mm}$. After adjustments were made for confounders, EL was found to be significantly associated with a low incidence of IVH grade $\geq$ III $(p=0.035)$, culture-proven sepsis $(p=0.004)$, NEC stage $\geq$ III $(p=0.022)$ and time on a mechanical ventilator $>4$ weeks $(p=0.007)$.

\section{Discussion}

In this retrospective cohort study of preterm neonates with HSPDA that is unresponsive to pharmacological treatment, there was no statistically significant difference in mortality rate between the PDA ligation and Nonligation groups. PDA ductal diameter $>2.0 \mathrm{~mm}$, low GA, low Apgar score at $5 \mathrm{~min}$, and histologic chorioamnionitis were related to the need for surgical ligation of HSPDA. Additionally, early surgical ligation was not significantly associated with increased mortality among preterm neonates with HSPDA. The LL group was significantly related to an increased risk of NEC (stage $\geq$ III), IVH (grade $\geq$ III), culture-proven sepsis and time on a mechanical ventilator $>4$ weeks.

\begin{tabular}{|c|c|c|c|c|c|}
\hline & $\begin{array}{c}\text { Medical treatment } \\
\text { favor }\end{array}$ & $\begin{array}{c}\text { Surgical ligation } \\
\text { favor }\end{array}$ & Adjusted OR & $95 \% \mathrm{Cl}$ & $p$ value \\
\hline Gestational age & $\mapsto-1$ & & 0.790 & $0.673-0.926$ & 0.004 \\
\hline Histologic chorioamnionitis & & $\longrightarrow$ & 2.007 & $1.043-3.861$ & 0.037 \\
\hline Pregnancy-induced hypertension & $\longmapsto$ & $\longrightarrow$ & 0.659 & $0.246-1.767$ & 0.407 \\
\hline Apgar score at 5 minutes & $\mapsto$ & & 0.810 & $0.668-0.983$ & 0.033 \\
\hline PDA ductal diameter $>2.0 \mathrm{~mm}$ & & $\longmapsto$ & 5.749 & $2.955-11.183$ & $<0.001$ \\
\hline & 0.1 & 10 & & & \\
\hline
\end{tabular}




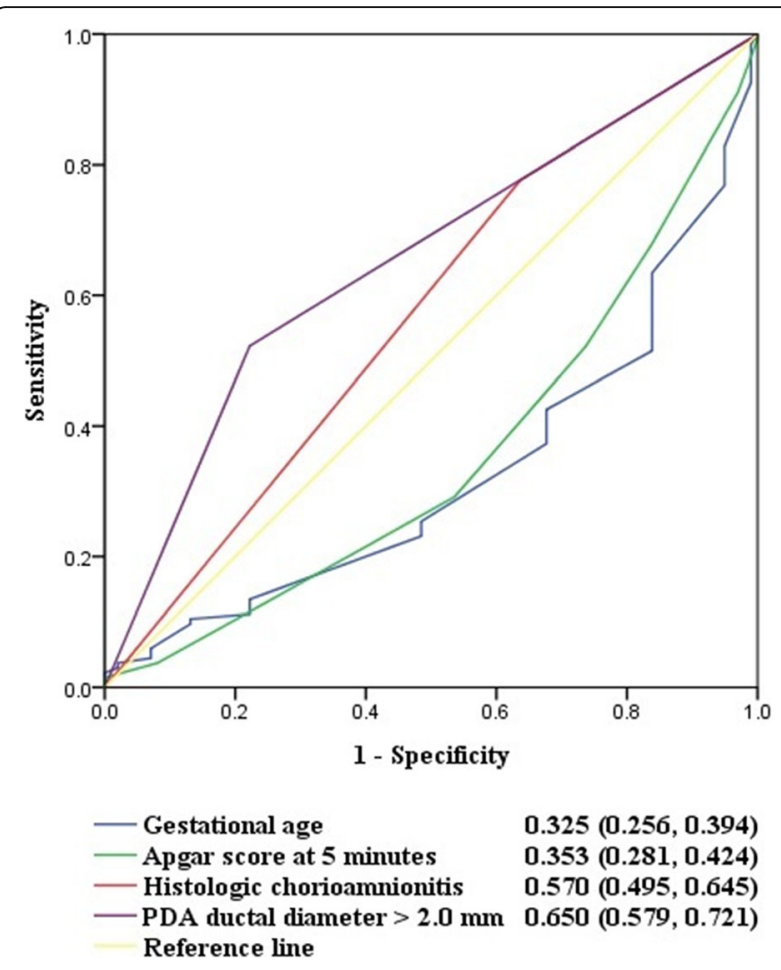

Fig. 3 Receiver operating characteristic curve for factors associated with PDA surgical ligation. Figures represent the area under the curve (95\% confidence interval). PDA, patent ductus arteriosus

The role of HSPDA surgical ligation in preterm neonates is still controversial. Although surgical treatment can close HSPDA immediately, multiple postoperative comorbidities such as left recurrent laryngeal nerve injury, bleeding, chylothorax, development of coarctation and acute hemodynamic compromise, can be associated with in-hospital mortality [5]. In addition, previous observational studies have demonstrated that surgical treatment is associated with an increased risk of chronic lung disease (CLD), ROP, and neurodevelopmental impairment (NDI) [5, 14-19]. In contrast, a recent observational study demonstrated that there was no significant difference in NDI between the PDA ligation and Nonligation groups [9]. Furthermore, another previous publication suggested that the preferred option for PDA after unsuccessful medical management should be surgical ligation to avoid prolonged low levels of cerebral saturation [20].

PDA surgical ligation is a viable option that is safe and effective [21], and it can be performed at the bedside in the NICU without transfer to the operating room $[5,22]$. In our cohort, no preterm neonates died during their operations, and there was no statistically significant difference in mortality rate between the PDA ligation and Nonligation groups, and between the EL and LL groups. Although this was a small retrospective study with only three preterm neonates who died and although its statistical power may be limited, this result was shown to be noninferior to those of previous publications [6, 9].

In this study, histologic chorioamnionitis, which is diagnosed by histologic biopsy of the maternal placenta, showed a significant association with factors related to PDA surgical ligation. The role of infection in maintaining the patency of PDA can be considered [23]. Infection may induce the production of cyclooxygenase (COX)-2 and inducible nitric oxide synthetase (iNOS), and together, they increase the production of vasodilatory prostaglandins such as COX-1 and NOS [24]. A preterm neonate born from a mother with chorioamnionitis can have PDA with a persistent opening due to increased levels of vasodilatory prostaglandins and nitric oxide. In addition, clinical factors such as the PDA ductal size and

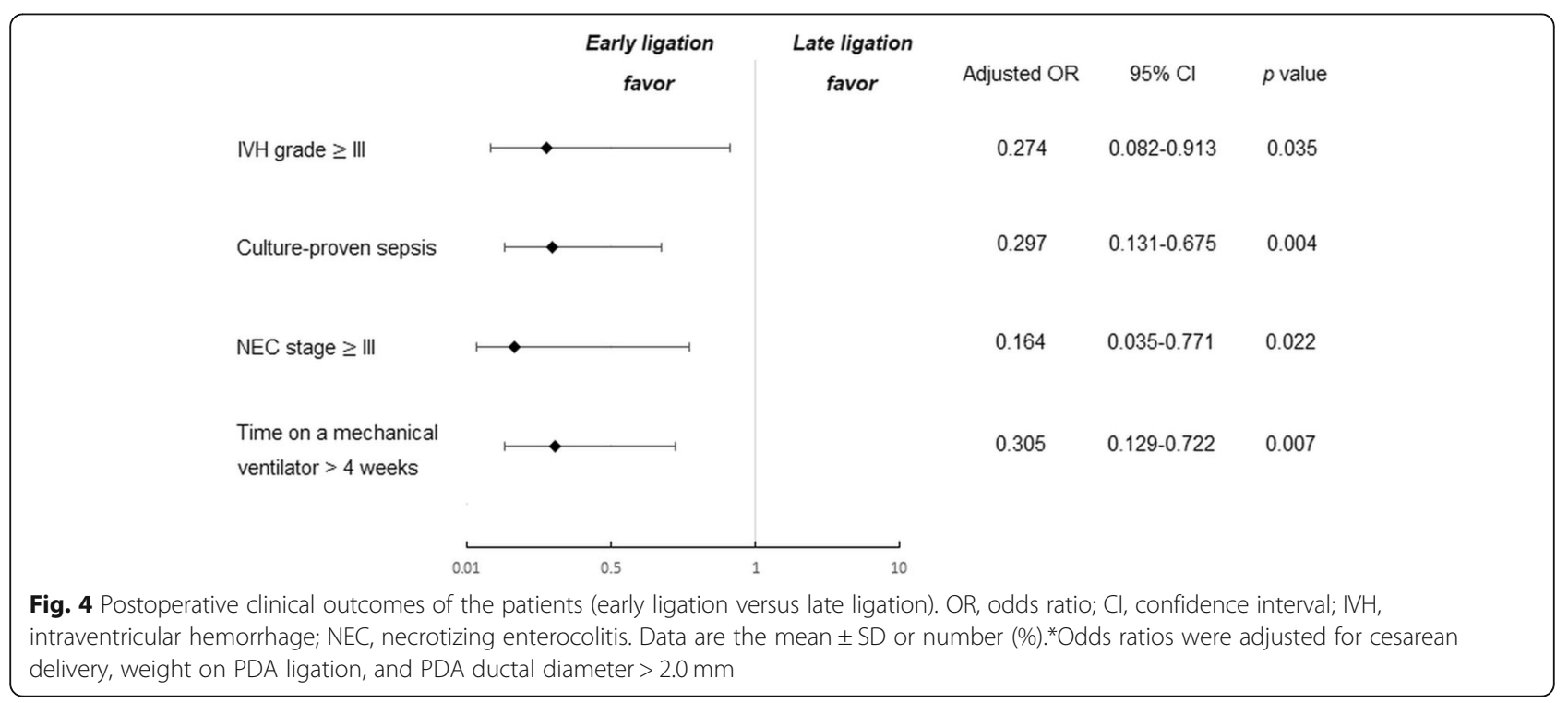


signs reflected in the Apgar score should be emphasized when considering surgical intervention to improve clinical outcomes.

In preterm neonates with HSPDA, it is important to determine the optimal timing of surgical ligation [21, 25]. Our results showed that the EL group was associated with lower odds of severe NEC and IVH than the LL group. This may be explained by the diastolic steal of systematic circulation through HSPDA, which can induce intestinal ischemia resulting in NEC, renal hypoperfusion, and a reduction in the blood flow rate in the middle cerebral artery [26] and increase the risk of IVH [27]. In our previous publication, early surgical ligation had the benefit of reducing the incidence of NEC and improving feeding intolerance [4]. The difference between this previous study and the current observational study is embodied, and there is a significant difference in severe NEC (stage $\geq$ III) between the EL and LL groups.

Additionally, sepsis with increased serum levels of inflammatory mediators or prostaglandins can be associated with smooth muscle relaxation of the ductus arteriosus [28]. Thus, as previously mentioned, the role of infection in maintaining the patency of PDA can be considered [23]. EL may reduce the duration of infection exposure and can be expected to minimize the risk of sepsis.

Prolonged patency of PDA increases pulmonary circulation that can be injurious to the capillary endothelium and stimulate an inflammatory cascade that results in pulmonary edema, CLD development, and increased ventilator support [29]. EL may diminish the period of exposure to HSPDA [30] and can decrease pulmonary edema [29] and facilitate earlier endotracheal extubation [9].

This study has several limitations. First, this was a small retrospective study with only 233 patients, and a randomized and prospective trial could not be performed. Thus, the statistical power of the population may be limited. Second, all operations were performed by one cardiac surgeon with a high level of experience in pediatric heart surgery. One goal of future research is to perform a large prospective multicenter study with longterm and close follow-up of preterm neonates with HSPDA that is refractory to pharmacological treatment.

\section{Conclusions}

Early surgical ligation minimizes adverse effects of HSPDA in predicted preterm neonates who subsequently require surgical treatment for PDA. This result suggests that in preterm neonates weighing less than $1500 \mathrm{~g}$ with HSPDA that is unresponsive to medical treatment, delayed ductal closure should be avoided to reduce severe NEC, severe IVH, culture-proven sepsis, and facilitate earlier endotracheal extubation. Avoidance of delayed surgical ligation after failure of pharmacologic closure may have beneficial outcomes in terms of postnatal morbidity among preterm neonates with risk factors in relation to HSPDA surgical ligation.

\section{Abbreviations}

HSPDA: Hemodynamically significant patent ductus arteriosus;

NEC: Necrotizing enterocolitis; IVH: Intraventricular hemorrhage; PDA: Patent ductus arteriosus; BPD: Bronchopulmonary dysplasia; NICU: Neonatal intensive care unit; NSAID: Nonsteroidal anti-inflammatory drug; DIC: Disseminated intravascular coagulation; EL: Early ligation; LL: Late ligation; ROP: Retinopathy of prematurity; PVL: Periventricular leukomalacia; ROC: Receiver operating characteristic; PIH: Pregnancy-induced hypertension; GA: Gestational age; Cl: Confidence interval; CLD: Chronic lung disease; NDI: Neurodevelopmental impairment; COX: Cyclooxygenase; iNOS: Inducible nitric oxide synthetase

\section{Acknowledgements}

Not applicable.

\section{Authors' contributions}

Lee $\mathrm{JH}$ : conceptualization, data curation, formal analysis, investigation, methodology, project administration, writing (original draft, review \& editing); Lee HJ: conceptualization, methodology, supervision, validation, writing (original draft, review \& editing). Park H: formal analysis, supervision, writing (review \& editing). Ahn J: investigation, supervision, validation, writing (review \& editing). Kim HS: project administration, resources, supervision, visualization, writing (review \& editing). Jang $\mathrm{HJ}$ : investigation, project administration, supervision, writing (review \& editing). Ro SK: project administration, resources, supervision, visualization, writing (review \& editing). Kim H: conceptualization, data curation, formal analysis, investigation, writing (review \& editing). All authors read and approved the final manuscript.

Funding

No funding was provided.

\section{Availability of data and materials}

Please contact the corresponding author for data requests.

Ethics approval and consent to participate

Our institutional review board approved this study, and the need for patient consent was waived (IRB number; HYUH 2019-07-004-003).

\section{Consent for publication}

Our institutional review board approved this study, and the need for patient consent was waived (IRB number; HYUH 2019-07-004-003). This manuscript has been reviewed and approved by all co-authors, and has not been submitted to any other journals for consideration for publication.

\section{Competing interests}

The authors declare that they have no competing interests.

\section{Author details}

${ }^{1}$ Department of Thoracic and Cardiovascular Surgery, Hanyang University Seoul Hospital, Hanyang University School of Medicine, 222-1, Wangsimni-ro, Seongdong-gu, Seoul 04763, South Korea. ²Department of Pediatrics, Hanyang University Seoul Hospital, Hanyang University School of Medicine, Seoul, Republic of Korea. ${ }^{3}$ Department of Thoracic and Cardiovascular Surgery, Hanyang University Guri Hospital, Hanyang University School of Medicine, Seoul, Republic of Korea.

Received: 10 March 2020 Accepted: 8 June 2020

Published online: 17 June 2020

\section{References}

1. Kitterman JA, Edmunds LHF, Gregory GA, Heymann MA, Tooley WH, Rudolph AM. Patent ductus arteriosus in premature infants: incidence, relation to pulmonary disease and management. N Engl J Med. 1972;287: 473-7.

2. Van Overmeire B, Smets K, Lecoutere D, Van de Broek H, Weyler J, Degroote $\mathrm{K}$, et al. A comparison of ibuprofen and indomethacin for closure of patent ductus arteriosus. N Engl J Med. 2000;343:674-81. 
3. Hoffman JI, Kaplan S. The incidence of congenital heart disease. J Am Coll Cardiol. 2002;39:1890-900.

4. Lee JH, Ro SK, Lee HJ, Park HK, Chung WS, Kim YH, et al. Surgical ligation on significant patent ductus arteriosus in very low birth weight infants: comparison between early and late ligations. Korean J Thorac Cardiovasc Surg. 2014:47:444-50.

5. Chang YH, Lee JY, Kim JE, Kim JY, Youn Y, Lee EJ, et al. The Aristotle score predicts mortality after surgery of patent ductus arteriosus in preterm infants. Ann Thorac Surg. 2013;96:879-84.

6. Youn Y, Moon CJ, Lee JY, Lee C, Sung IK. Timing of surgical ligation and morbidities in very low birth weight infants. Medicine. 2017;96(14):1-4

7. Shimada S, Kasai T, Konishi M, Fujiwara T. Effects of patent ductus arteriosus on left ventricular output and organ blood flows in preterm infants with respiratory distress syndrome treated with surfactant. J Pediatr. 1994;125: 270-7.

8. Lee HJ, Sim GH, Jung KE, Lee JA, Choi CW, Kim EK, et al. Delayed closure effect in preterm infants with patent ductus arteriosus. Korean J Pediatr. 2008;51:1065-70.

9. Weisz DE, Mirea L, Resende MH, Ly L, Church PT, Kelly E, et al. Outcomes of surgical ligation after unsuccessful pharmacotherapy for patent ductus arteriosus in neonates born extremely preterm. J Pediatr. 2018;185:292-6.

10. Volpe JJ. Intraventricular hemorrhage in the premature infant - current concepts. Part I. Ann Neurol. 1989;25:3-11.

11. Kamitsuka MD, Horton MK, Williams MA. The incidence of necrotizing enterocolitis after introducing standardized feeding schedules for infants between 1250 and 2500 grams and less than 35 weeks of gestation. Pediatrics. 2000;105:379-84.

12. Jobe AH, Bancalari E. Bronchopulmonary dysplasia. Am J Respir Cirt Care Med. 2001;163:1723-9.

13. International Committee for the Classification of Retinopathy of Prematurity The international classification of retinopathy of prematurity revisited. Arch Ophthalmol. 2005;123:991-9.

14. Kabra NS, Schmidt B, Roberts RS, Doyle LW, Papile L, Fanaroff A, et al. Neurosensory impairment after surgical closure of patent ductus arteriosus in extremely low birth weight infants: results from the trial of indomethacin prophylaxis in Preterms. J Pediatr. 2007;150:229-34.

15. Weisz DE, More K, McNamara PJ, Shah PS. PDA ligation and health outcomes: a meta-analysis. Pediatrics. 2014;133:e1024-46.

16. Mirea L, Sankaran K, Seshia M, Ohlsson A, Allen AC, Aziz K, et al. Treatment of patent ductus arteriosus and neonatal mortality / morbidities: adjustment for treatment selection bias. J Pediatr. 2012;161:689-94.

17. Madan JC, Kendrick D, Hagadorn JI, Frantz ID 3rd. Patent ductus arteriosus therapy: impact on neonatal and 18-month outcome. Pediatrics. 2009;123: 674-81.

18. Clyman R, Cassady G, Kirklin JK, Collins M, Philips JB. The role of patent ductus arteriosus ligation in bronchopulmonary dysplasia: reexamining a randomized controlled trial. J Pediatr. 2009;154:873-6.

19. Chorne N, Leonard C, Piecuch R, Clyman Rl. Patent ductus arteriosus and its treatment as risk factors for neonatal and neurodevelopmental morbidity. J Pediatr. 2007;119:1165-74.

20. Lemmers PM, Benders MJ, D'Ascenzo R, Zethof J, Alderliesten T, Kersbergen $\mathrm{KJ}$, et al. Patent ductus arteriosus and brain volume. Pediatrics. 2016;137(4): e20153090.

21. Vida VL, Lago P, Salvatori S, Boccuzzo G, Padalino MA, Milanesi O, et al. Is there an optimal timing for surgical ligation of patent ductus arteriosus in preterm infants? Ann Thorac Surg. 2009;87:1509-16.

22. Avsar MK, Demir T, Celiksular C, Zeybek C. Bedside PDA ligation in premature infants less than 28 weeks and 1000 grams. J Cardiothorac Surg. 2016:11:146-50.

23. Park HW, Choi YS, Kim KS, Kim SN. Choriamnionitis and patent ductus arteriosus: a systematic review and meta-analysis. PLoS One. 2015;10(9): e0138114.

24. Yeung MY. Hypotension, persistent ductus arteriosus and the underlying adrenal insufficiency in low gestation newborns. World J Pediatr. 2006;1:8-13.

25. Raval MV, Laughon MM, Bose CL, Phillips JD. Patent ductus arteriosus ligation in premature infants: who really benefits, and at what cost? J Pediatr Surg. 2007:42:69-75.

26. Weir FJ, Ohlsson A, Myhr TL, Fong K, Ryan ML. A patent ductus arteriosus is associated with reduced middle cerebral artery blood flow velocity. Eur J Pediatr. 1999:158:484-7.
27. Osborn DA, Evans N, Kluckow M. Effect of early targeted indomethacin on the ductus arteriosus and blood flow to the upper body and brain in the preterm infant. Arch Dis Child Fetal Neonatal Ed. 2003;88:F477-82.

28. Vucovich MM, Cotton RB, Shelton EL, Goettel JA, Ehinger NJ, Poole SD, et al. Aminoglycoside-mediated relaxation of the ductus arteriosus in sepsisassociated PDA. Am J Physiol Heart Circ Physiol. 2014;307(5):H732-40.

29. Mashally S, Nield LE, McNamara PJ, Martins FF, El-Khuffash A, Jain A, et al. Late oral acetaminophen versus immediate surgical ligation in preterm infants with persistent large patent ductus arteriosus. J Thorac Cardiovasc Surg. 2018;156:1937-44.

30. Noori S, McCoy M, Friedlich P, Bright B, Gottipati V, Seri I, et al. Failure of ductus arteriosus closure is associated with increased mortality in preterm infants. Pediatrics. 2009;123:e138-44.

\section{Publisher's Note}

Springer Nature remains neutral with regard to jurisdictional claims in published maps and institutional affiliations.
Ready to submit your research? Choose BMC and benefit from:

- fast, convenient online submission

- thorough peer review by experienced researchers in your field

- rapid publication on acceptance

- support for research data, including large and complex data types

- gold Open Access which fosters wider collaboration and increased citations

- maximum visibility for your research: over $100 \mathrm{M}$ website views per year

At BMC, research is always in progress.

Learn more biomedcentral.com/submissions 